http://jmscr.igmpublication.org/home/ ISSN (e)-2347-176x ISSN (p) 2455-0450 crossref DOI: https://dx.doi.org/10.18535/jmscr/v8i5.68

\title{
Psychiatric Co-morbidity in Chronic Skin Diseases
}

Authors

\author{
Abhay Kumar ${ }^{1}$, Krishna Kumar Singh ${ }^{2 *}$, Guddi Rani Singh ${ }^{3}$ \\ ${ }^{1}$ Assistant Professor, Dept. of Psychiatry, ANMCH, Gaya, Bihar \\ ${ }^{2}$ Associate Professor, Dept. of Psychiatry, IGIMS, Patna, Bihar \\ ${ }^{3}$ Assistant Professor, Dept. of Pathology, DMCH, Darbhanga, Bihar \\ *Corresponding Author \\ Dr Krishna Kumar Singh \\ Associate Professor, Dept. of Psychiatry, IGIMS, Patna, Bihar, India
}

\begin{abstract}
Objective: The aim of study was to assess the comorbidity of psychiatric illnesses in the patients suffering from chronic skin Diseases.

Material and Methods: One hundred consecutive patients attending OPD of Dept. of Dermatology, ANMCH, Gaya, Bihar were studied. Patients were examined through Psychiatric interview \& screened through Hospital anxiety and depression scale after taking informed consent.

Discussion \& Results: Out of these 40 patients $70 \%$ (28/40) had anxiety disorder and 30\% (12/40) had depressive disorder or dysthymia. Patients of anxiety disorders 35.7\% (10/28) had mixed anxiety disorder, $25.7 \%$ had Generalized anxiety disorder, 21.4\% (6/28) had panic disorder, 17.85(5/28) had somatization disorder. Patients of depressive disorders $66.66 \%$ had major depressive disorder and $33.33 \%$ had dysthymia.

Conclusion: There is a high rate of psychiatric problems in patients with chronic Skin Diseases.

Keywords: chronic skin Diseases, co-morbid psychiatric illness, Anxiety, depression.
\end{abstract}

\section{Introduction}

Skin is the largest organ of the body. It plays a major role in social and sexual communication as it determines to a great extent in its appearance. A healthy skin is essential for a person`s physical, mental and social wellbeing and his/her emotions. $^{1-2}$

Perception of surface alteration as a handicap and its evaluation in terms of quality and quantity of damage varies from individual to individual and from dermatosis to dermatosis. Psychiatric disturbance and psycho-social impairment is reported in at least $30 \%$ of the dermatological patients. Among all psychiatric disorders anxiety and depression are observed more commonly and their recognition is important in the management of the disease. ${ }^{3}$

During the consultation in dermatology department the psychiatric impacts are often underestimated or missed. It may be due to the poor training of medical students during their training in MBBS course, Post graduation course about psychiatric illnesses or due to overloaded OPD environment. These factors highly matter in state like Bihar where population density is much more than the nation average. 
Hence, the psychological aspects of dermatological problems can't be underestimated because management of co-morbid psychiatric illness ultimately affects the overall satisfaction, feeling of wellbeing, and less chances of drop out during management of dermatological illnesses.

\section{Aim of Study}

- To identify the comorbid psychiatric illnesses in dermatology.

- To identify the need for minimum training in Psychiatry required in dermatology.

\section{Material \& Methods}

The study consisted of 100 consecutive patients of any chronic dermatological diseases/problems attending to dermatology department at $\mathrm{ANMCH}$, Gaya, Bihar.

\section{Inclusion Criteria}

- Patients having chronic dermatological diseases/problems.

- Patients having vague symptoms which are not related to dermatological problems.

- No age restriction and all socio-economic strata.

- Patients who are cooperative, willing and are able to discuss their problems.

\section{Exclusion Criteria}

- Patients having history of treatment for psychiatric, neurological, medical illnesses prior to dermatological problems and currently receiving psychiatric treatment.

- Patients who do not want to participate in the study.

\section{Tools}

- Semi Structured Performa for demographic data and clinical history.

- International classification of diseases (ICD- 10) and Diagnostic and Statistical manual of mental disorders.

- MSE (mental status examination)

- Hospital anxiety and depression scale

\section{Procedure}

The study was cross sectional study done on 100 consecutive patients suffering from chronic dermatological problems at skin OPD at ANMCH, Gaya, Bihar are examined through above prescribed tools. All the relative details regarding history, examination, and treatment were recorded on pre-designed Performa. Statistical analysis was performed on variable interest of study including sex, marital and employment status as well as dermatological diagnosis. The relationship between disease variables and psychiatric illness was observed. Information obtained was kept confidential and due attention to consent was given.

\section{Discussion \& Results}

This was a cross-sectional observational study conducted in patient attending the dermatological OPD and results may not be generalized to general populations. Findings suggest that there was a high psychiatric comorbidity in patients with dermatological illnesses. Leprosy, Psoriasis and Acne were the most common dermatological illnesses associated with psychiatric comorbidity. Psychiatric co morbidity was one of the major health problems in dermatological cases.

This was supported by study result that Eczema was the most common disease in both genders. Acne was the next common disease in female whereas dermatophytes were in male and was inconsistent that Leprosy was the least common disease in both gender. ${ }^{4}$

Out of 100 consecutive patients at dermatology OPD, $65 \%$ patients were female and rest were males. Assessment through psychiatric interview and Mental Status Examination $40 \%$ were suffering from psychiatric illnesses and $60 \%$ have no psychiatric problems.

Out of these 40 patients $70 \%$ (28/40) had anxiety disorder and 30\% (12/40) had depressive disorder or dysthymia. In Patients of anxiety disorders, $35.7 \%(10 / 28)$ had mixed anxiety disorder, $25.7 \%$ had Generalized anxiety disorder, $21.4 \%(6 / 28)$ had panic disorder, $17.85(5 / 28)$ had somatization 
disorder. In Patients of depressive disorders, $66.66 \%$ had major depressive disorder and $33.33 \%$ had dysthymia.

These results were supported by study result that Spielberger questionnaires indicated $45 \%$ and $18 \%$ of case and control groups had anxiety which was statistically significant $\mathrm{p}<.001$. Psoriatic patients showed higher level of anxiety than the control group. The Beck Depression questionnaires indicated that $67 \%$ and $12 \%$ of the patients in the case and control groups had depression, respectively. This result demonstrated significant differences between both case and control groups $(\mathrm{p}<.001)^{6}$.

Patients' needs arise from the disease itself, from the effects of the disease on the patient's life and from the process of care. ${ }^{7}$

There are variations in the prevalence of psychiatric disorders in dermatological patients across several studies using different methods and instruments which are as below.

Psychiatric illnesses are not uncommon among people with established dermatological disorders. In a study psychiatric illness was $40 \%$ among new attendees at dermatology OPD. ${ }^{8}$

One study using HADS has estimated the prevalence of psychological symptoms in dermatological patients to be ranging between $25.9 \%$ and $31 \%$. $^{9}$

While the prevalence of psychiatric disorder inpatient attending a dermatological outpatient clinic, using 12- item General Health Questionnaire (GHQ), was found to be $33.4 \%$ in another study. ${ }^{10}$ Other two studies using same instrument (12- items GHQ) reported less but significant psychiatric co- morbidity ranging between $7.6 \%$ and $25.2 \% .^{11-12}$
Higher prevalence estimates were also documented by using GHQ-28 with psychiatric co-morbidity approaching $51.3 \% .^{13}$

Using DSM - IV criteria has shown that about $38 \%$ of dermatological patients received DSM IV diagnosis; most commonly mood disorder (20\%) and anxiety disorder (16\%).By using criteria for psychosomatic research (DCPR), $48 \%$ of patients have also received a DCPR diagnosis; most commonly demoralization irritable type of mood, type A behaviour and abnormal behaviour. $^{14}$

Finding approximately similar to our results were reported by study using HADS score indicating higher prevalence of anxiety (28\%) than depression (20\%). ${ }^{15}$

In another study depressive disorders are common among patients with dermatological disorders occurring in $30 \%$ of cases, which are more common than to patient in general population where prevalence of depression is about $22 \% .^{16}$

In our study, we found that anxiety disorders are more prevalent than depressive disorder.

Table1 Psychiatric diagnosis associated in patients attending Dermatology OPD

\begin{tabular}{|l|c|}
\hline Psychiatric disorder & Percentage \\
\hline Anxiety disorder & 28 \\
\hline Depressive disorder & 12 \\
\hline No psychiatric diagnosis & 60 \\
\hline
\end{tabular}

Table 2 Depression associated with patients of skin disorder.

\begin{tabular}{|l|c|}
\hline Depressive disorder & Percentage \\
\hline Major depressive disorder & 66.66 \\
\hline Dysthymia & 33.33 \\
\hline
\end{tabular}




\section{Graph 1}

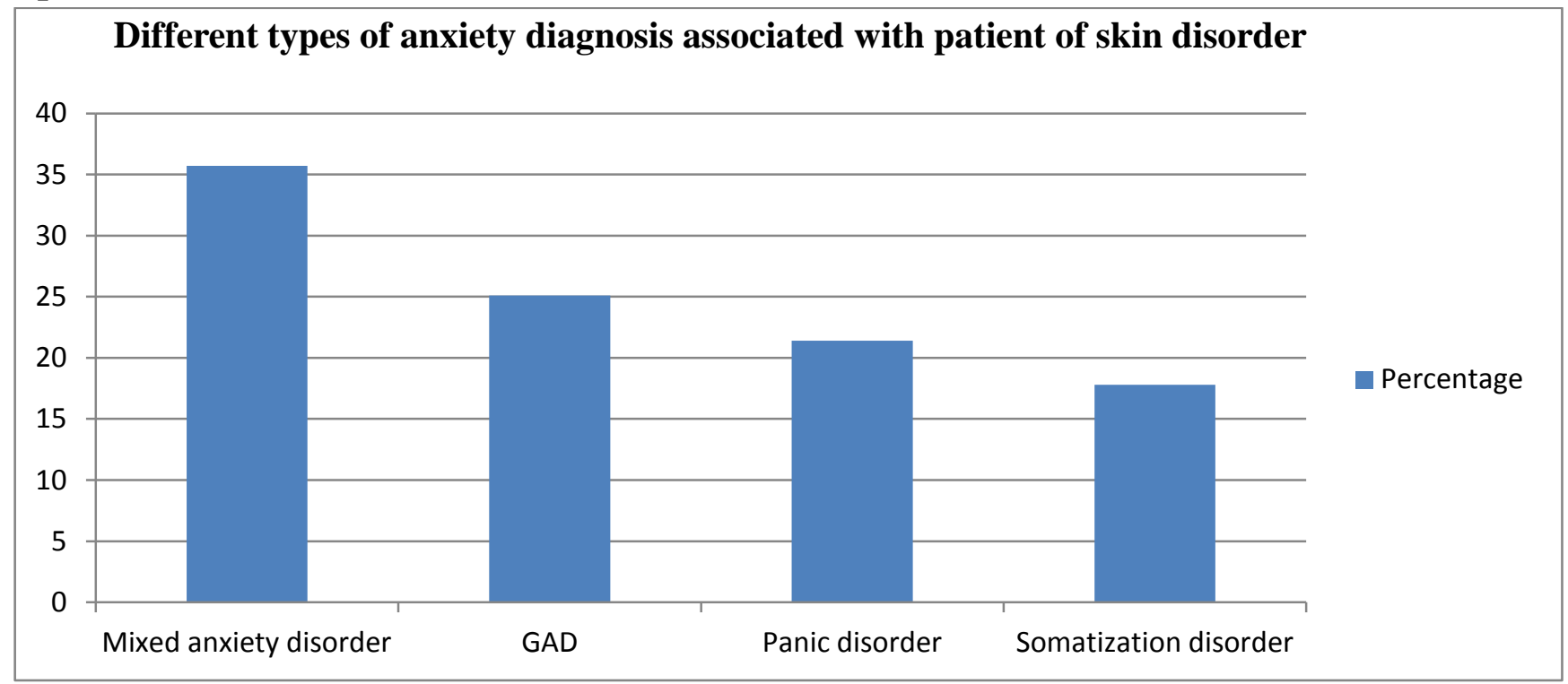

\section{Conclusion}

The study shows that psychiatric illnesses are very common in patients with chronic Skin Diseases. Generalized anxiety disorder, mixed anxiety and depression are most common entities.

Consideration of psychiatric and psychosocial factors is important both for the management and for some aspect of prevention of wide range of dermatological disorders. So management of comorbid psychiatric illness with dermatological illness is essential for patient's wellbeing and may influence the better outcome and drop out during management.

\section{Financial support and sponsorship: Nil Conflicts of interest: Nil}

\section{References}

1. Aktan S, Ozmen E, Sanli B. Psychiatric disorders in patients attending a dermatology outpatient clinic. Dermatology 1998; 197: 230-4.

2. Grossbart, T. (2010) The Psychology of Physical Symptoms. Journal of American Medical Assessment. Platter File 3.11. Platter: Psychosomatic Dermatitis.

3. Gupta MA, Gupta AK. Psychiatric and psychological comorbidity in patients with dermatological disorders. Am J Clin Dermatol 2003; 4: 833-42.

4. Shrestha P, Mikrani JA. Pattern of dermatological disease and its relation to gender in Lumbini Medical College Teaching Hospital. Journal of Lumbini Medical College, 2015; 3(1):16-8. doi: 10.22502/ jlmc.v3i1.63.

5. Bhatia MS, Chandra R, Bhattacharya SN, Imran M. Pattern of psychiatric morbidity and and dysfunctions in patients with psoriasis. Delhi Psychiatry Bulletin 2006 Oct; 9(2):138-41.

6. Golpour M, Hosseini SH, Khademloo M, Ghasemi M, Ebadi A, Koohkan F, Shahmohammadi S. Depression and Anxiety Disorders among Patients with Psoriasis: A Hospital-Based Case-Control Study. Dermatology Research and Practice, 2012 (2012), 5 http://dx.doi.org/10.1155/2012/381905

7. Aslam, R., Qadir, A. and Asad, F. (2007) Psychiatric Morbidity in Dermatological Outpatients: An Issue to Be Recognized. Journal of Pakistan Association of Dermatologists, 17, 235-223.

8. Aktan, S., Ozmen, E. and Sanli, B. (1998) Psychiatric Disorders in Patients Attending 
a Dermatology Outpatient Clinic.

Dermatology, 197, 230-234.

9. Filaković, P., Petek, A., Koić, O., Radanović-Grgurić, L. and Degmečić, D. (2009) Comorbidity of Depressive and Dermatologic Disorders-Therapeutic Aspects. Psychiatria Danubina, 21, 401410.

10. Finlay AY. Dermatology patients: what do they need? Clin Exp Dermatol 2000; 25: 444-50.

11. Picardi, A., Pasquini, P., Abeni, D., Fassone, G., Mazzotti, E. and Fava, G.A. (2005) Psychosomatic Assessment of Skin Diseases in Clinical Practice. Psychotherapy and Psychosomatics, 74, 315-322.

12. Picardi, A., Abeni, D., Renzi, C., Braga, M., Melchi, C.F. and Pasquini, P. (2003) Treatment Outcome and Incidence of Psychiatric Disorders.

13. Picardi, A., Abeni, D., Melchi, C.F., Puddu, P. and Pasquini, P. (2000) Psychiatric Morbidity in Dermatological Outpatients. An Issue to Be Recognized. British Journal of Dermatology, 143, 98399.

14. Windemuth, D., Stücker, M., Hoffmann, K. and Altmeyer, P. (1999) Prevalence of Psychological Symptoms in Dermatologic Patients of an Acute Clinic. Der Hautarzt, 50, 338-343.

15. Wessely SC, Lewis GH. Classification of psychiatric morbidity in attenders at dermatology clinic. Br J Psychiatry 1989; 55: 686-91. 